\title{
Computer Aided Modeling and Deign of a New Magnetic Sealing Mechanism in Engineering Applications
}

\author{
Jeremy (Zheng) LI \\ School of Engineering, University of Bridgeport, Bridgeport, USA \\ E-mail: zhengli@bridgeport.edu \\ Received June 6, 2009; revised August 3, 2009; accepted August 10, 2009
}

\begin{abstract}
This article introduces a new type of magnetic sealing mechanism that reduces the lubrication oil pollution and media gaseous leakage in general reciprocating machinery including air compressors and refrigerators. The feasible function and reliable performance of this new sealing mechanism are introduced and analyzed in this paper. The computer aided design, modeling and analysis are being used to study this new sealing mechanism, and the prototype of this sealing mechanism is being tested. The study indicated the proper function of this sealing mechanism. The major advantages of this sealing mechanism include: improved sealing capacity to prevent the gaseous leakage and oil leakage, simple and compact in structure, lower precision requirement on surfaces of reciprocating pistons and shafts in production and manufacturing, and longer services in sealing life span. Also there is almost no frictional loss during the reciprocating motion of piston or shaft.
\end{abstract}

Keywords: Magnetic Sealing, Magnetic Flux, Reciprocating Machinery, Self-Lubricated System

\section{Introduction}

The gaseous leakage and oil pollution in reciprocating machines including compressors and refrigerators are common problems that have not been well resolved and it directly affects the machinery performance [1-4]. The design and development of new sealing mechanism are continued in these years [5-8].

In this research, a new magnetic sealing mechanism using rare-earth magnet as permanent magnet is developed to solve these problems based on theoretic analysis, computational modeling simulation, and prototype tests. The permanent magnet is made from the materials that stay magnetized. Materials that can be magnetized are called ferromagnetic including rare earth magnets. The current research and development of rare earth permanent magnets have brought the renovation in the field of magnetic separation and provided the magnetic products that are an order of magnitude stronger than that of conventional ferrite magnets. This leads to the development of high-intensity magnetic circuits that operated energy free and surpasses the electromagnets in strength and effectiveness. Common applications of rare-earth magnets include: computer hard drives, audio speakers, bicy- cle dynamos, fishing reel brakes, mag-lev wind turbines, and LED throwies.

The prototype testing of this new magnetic sealing mechanism indicated that this sealing mechanism can significantly reduce the leakage problem in reciprocating machines including compressors and oil pollution in cryogenic regenerator. It also shows that this sealing mechanism can replace the oil separation system in refrigerating compressors. Through the prototype tests, the sealing function of this new mechanism is better than regular rubber seal, diaphragm seal, corrugated pipe seal and magnetic fluid seal.

\section{Magnetic Circuit in Sealing Mechanism}

The rare-earth magnet steel can be performed as a permanent magnet steel which has the higher density of magnetic flux $\mathrm{Br}$, strong magnetic field $\mathrm{H}_{\mathrm{g}}$, and larger product of magnetism and energy $(\mathrm{BH})_{\max }$ as shown in Figure 1. All these good features allow the magnetic particles to be firmly adhered onto the inside wall of magnet steel. The major advantages of this magnetic circuit include higher $\mathrm{Br}$ in working gap of the circuit, longer and durable in sealing lifetime, compact in system configuration, light in unit weight, higher in performance efficien- 


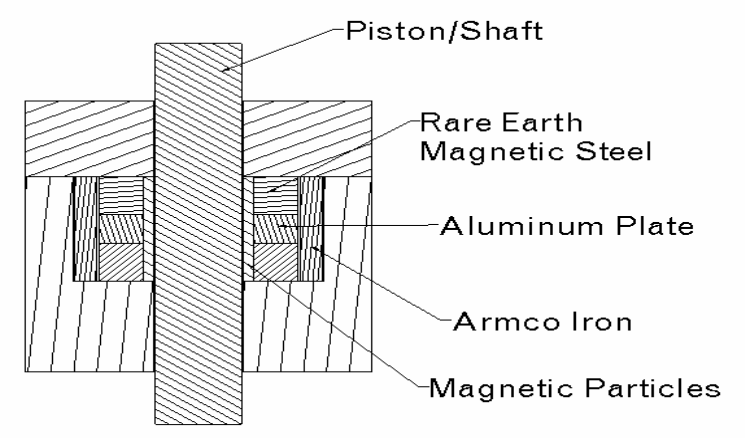

Figure 1. Magnetic sealing mechanism.

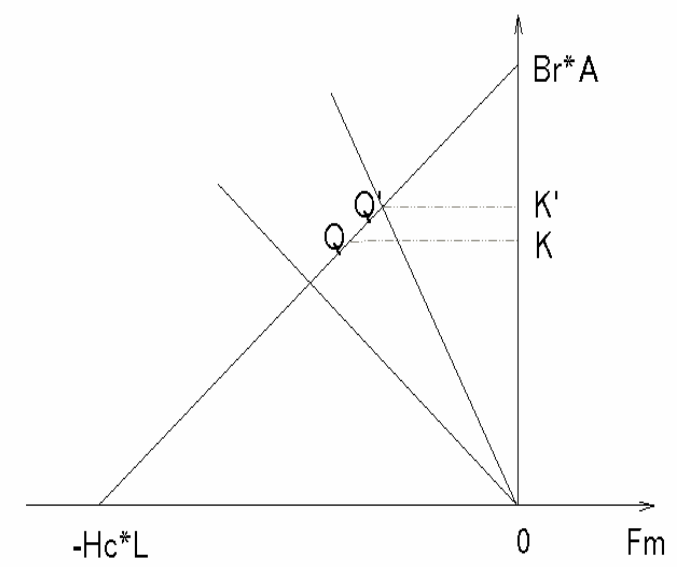

Figure 2. Magnetic curve of circuit.

cy, and stable in sealing functioning.

The concept of this new magnetic sealing mechanism can be briefly described as follows. When piston/shaft reciprocates inside of the cylinder, lubricating oil is sealed by magnetic particles, which are firmly adhered on the inside surface of magnet steel, as oil particles move to the seal. Then the oil droplets drop to the main shaft chamber at the bottom of compressors by its gravity which can prevent the oil in crank chamber from entering the gas cylinder. Also the gaseous leakage can be prevented because the gas could not pass through the strong adhesive layers of magnetic particles. In this new magnetic sealing design, two critical factors that should be considered to keep its well function are density of magnetic flux and magnetic stability of the magnet steel. Thus the magnetic flux in magnetic circuit of this sealing mechanism must be maintained over a long period of time and magnetic field of this magnet steel should be stable enough to withstand the external/disturbed magnetic fields, temperature change, mechanical vibration/shock, and severe environmental fluctuation. The surplus density of magnetic flux $\mathrm{Br}$, surplus intensity of magnetic field $\mathrm{H}_{\mathrm{g}}$, and maximum product of magnetism and energy $(\mathrm{BH})_{\max }$ are required to keep their peak val- ues in this magnetic sealing mechanism design.

The magnetic circuit in this sealing mechanism is in static condition which can be analyzed using ampere enclosed circuit and H-B curve of this rare-earth magnet steel. This magnetic circuit can be considered as a series magnetic circuit mainly made up from magnet steel and working gap. Refer the Figure 1, the following equations can be derived:

$$
\begin{array}{r}
\mathrm{H} * \mathrm{~L}+\mathrm{H}_{\mathrm{g}} * \mathrm{~L}_{\mathrm{g}}=0 \\
\mathrm{H} * \mathrm{~L}=-\frac{L g * \Phi}{U_{0} * A g}
\end{array}
$$

Let $\operatorname{Fm}(\Phi)=\mathrm{H} * \mathrm{~L}$, the intersection of $\operatorname{Fm}(\Phi)$ and straight line $-\left[\mathrm{L}_{\mathrm{g}} /\left(\mathrm{U}_{0} * \mathrm{~A}_{\mathrm{g}}\right)\right] * \Phi$ at ordinate in Figure 2 is the magnetic flux in working gap that required to be determined. This gap decreases from $\mathrm{Lg}$ to $\mathrm{Lg}$ ' after magnetic particles being added into the space in magnetic circuit gap. When the thickness of magnetic particles in the gap between surfaces of magnet steel and cylinder changes from 0 to $\mathrm{b}$, the working point of magnet steel changes along the straight line QK. The corresponding solution of magnetic flux in working gap can be found from line QK. The magnetic field is well distributed / maintained in this sealing mechanism that has been verified from computational modeling simulation. The coefficient of magnetic efficiency $f$ is used to judge if the magnetic field in this sealing mechanism is properly designed. Here,

$$
\mathrm{f}=\frac{B g^{2} * V g}{(B * H)_{\max } * V}
$$

The higher $f$ value indicates more feasible and reasonable design on the magnetic circuit. The $f$ value is normally $40 \%$ in standard conditions. The computational modeling solution shows that $\mathrm{f}$ value in this sealing magnetic mechanism is $48.5 \%$ which verifies the proper magnetic circuit design in this sealing mechanism.

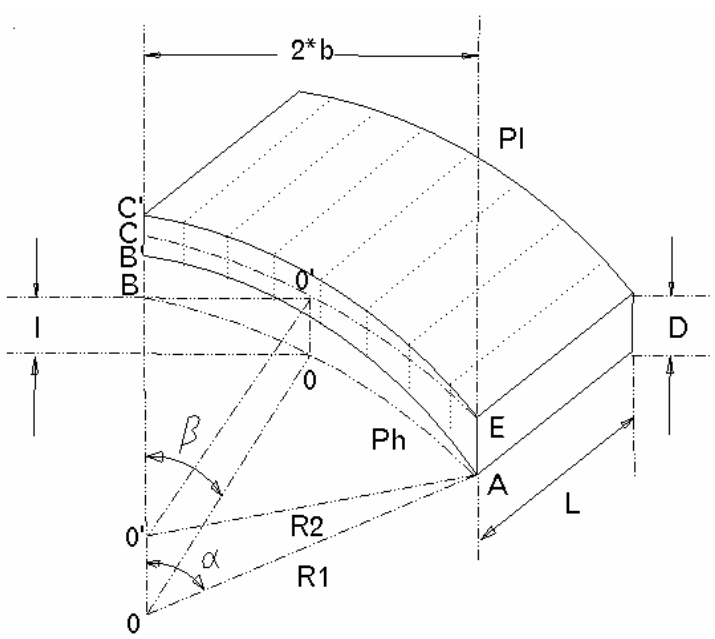

Figure 3. Cross section view of magnetic steel. 


\section{Analysis of Sealing Capacity}

The formula of sealing capacity $\Delta \mathrm{P}$ can be derived from energy balancing theory as follows.

Referring the cross section of this magnetic seal in Figure 3,

$$
\begin{aligned}
& \mathrm{R}_{1}=\frac{2 * b}{\sin (\alpha)} \\
& \mathrm{R}_{2}=\frac{2 * b}{\sin (\beta)} \\
& \mathrm{S}_{1}=\mathrm{R}_{1} * \alpha \\
& \mathrm{S}_{2}=\mathrm{R}_{2} * \beta \\
& \Delta \mathrm{S}=\mathrm{S}_{2}-\mathrm{S}_{1}=\left[\frac{\beta}{\sin (\beta)}-\frac{\alpha}{\sin (\alpha)}\right] * 2 * \mathrm{~b} \\
&\left|O O^{\prime}\right|=2 * \beta *[\operatorname{ctg}(\alpha)-\operatorname{ctg}(\beta)]
\end{aligned}
$$

Because the work that each magnetic line of force applied is $T^{*} \Delta \mathrm{S}$, total work that magnetic lines of force applied in magnetic circuit is:

$$
\mathrm{W}_{1}=\mathrm{B} * \mathrm{D} * \mathrm{~T} * 2 \mathrm{~b} *\left[\frac{\beta}{\sin (\beta)}-\frac{\alpha}{\sin (\alpha)}\right]
$$

At the same time, the work that media pressure applied to the body of magnetic particles is:

$$
\mathrm{W}_{2}=4 * \mathrm{~b}^{2} * \Delta \mathrm{P} *\left[\frac{\sin (\alpha)+\pi *[\cos (\alpha)-2]^{2}}{8 * \sin (\alpha)-\frac{\sin (\alpha)}{4}}\right]
$$

Based on energy balancing theory, the work that mag- netic lines of force applied in magnetic circuit should be equal to the work that media pressure exerted to the body of magnetic particles. So,

$$
\Delta \mathrm{P}=\frac{\left(\frac{1}{2}\right) * B^{*} D^{*} T^{*}[\sin (\alpha)-\alpha]}{\left\{2 * b *(\sin \alpha)+\frac{\alpha}{8} *\left[\cos ^{2}(\alpha)-4 * \cos (\alpha)+3\right]\right\}}
$$

This formula can be calculated by computational modeling with numerical solution. The optimized computational simulation indicated that, when $\alpha$ and $\beta$ are changed to certain values, the $\Delta \mathrm{P}_{\max }$ can be determined as follows:

$$
\Delta \mathrm{P}_{\max }=\frac{C^{*} B^{*} D^{*} T}{2 * b}=28.5 \mathrm{Kg} / \mathrm{cm}^{2}
$$

This result shows that the seal capacity of this magnetic sealing mechanism can prevent the oil leakage/pollution from crank chamber into the cylinders of reciprocating machinery and refrigerating regenerators. It can also keep the compressors from gaseous leakage.

\begin{tabular}{|c|c|c|c|c|c|}
\hline $\begin{array}{l}\text { Piston Linear Speed } \\
\text { (Ft/Min) }\end{array}$ & $\begin{array}{c}\text { Estimated Air Leak- } \\
\text { age (SCFM) }\end{array}$ & $\begin{array}{l}\text { Piston Linear Speed } \\
\text { (Ft/Min) }\end{array}$ & $\begin{array}{c}\text { Estimated Air Leak- } \\
\text { age (SCFM) }\end{array}$ & $\begin{array}{l}\text { Piston Linear Speed } \\
\text { (Ft/Min) }\end{array}$ & $\begin{array}{c}\text { Estimated Air Leak- } \\
\text { age (SCFM) }\end{array}$ \\
\hline 5 & 0.001 & 45 & 0.036 & 90 & 0.083 \\
\hline 10 & 0.003 & 50 & 0.043 & 100 & 0.088 \\
\hline 15 & 0.006 & 55 & 0.048 & 105 & 0.092 \\
\hline 20 & 0.010 & 60 & 0.054 & 110 & 0.095 \\
\hline 25 & 0.014 & 65 & 0.061 & 115 & 0.099 \\
\hline 30 & 0.019 & 70 & 0.066 & 120 & 0.104 \\
\hline 35 & 0.025 & 75 & 0.071 & 125 & 0.111 \\
\hline 40 & 0.031 & 80 & 0.077 & 130 & 0.119 \\
\hline
\end{tabular}
The above mechanism analysis and computational simulation have been verified through the prototype tests.

\begin{tabular}{|c|c|c|c|c|c|}
\hline Air Pressure (PSIG) & $\begin{array}{c}\text { Estimated Air Leak- } \\
\text { age (SCFM) }\end{array}$ & Air Pressure (PSIG) & $\begin{array}{c}\text { Estimated Air Leak- } \\
\text { age (SCFM) }\end{array}$ & Air Pressure (PSIG) & $\begin{array}{c}\text { Estimated Air Leak- } \\
\text { age (SCFM) }\end{array}$ \\
\hline 50 & 0.002 & 450 & 0.030 & 800 & 0.063 \\
\hline 100 & 0.005 & 500 & 0.033 & 850 & 0.067 \\
\hline 150 & 0.007 & 550 & 0.037 & 900 & 0.070 \\
\hline 200 & 0.011 & 560 & 0.042 & 950 & 0.074 \\
\hline 250 & 0.015 & 600 & 0.045 & 1000 & 0.079 \\
\hline 300 & 0.018 & 650 & 0.049 & 1050 & 0.083 \\
\hline 400 & 0.026 & 750 & 0.058 & 1150 & 0.094 \\
\hline
\end{tabular}
Furthermore, the sealing capacity in this mechanism can be improved by increasing the number of this magnetic seal, improving the magnetic material composite and optimizing the magnetic circuit design.

\section{Prototype Testing Results}

The prototype of this new magnetic sealing mecha-

Table 1. Estimated air leakage at different piston linear speed.

Table 2. Estimated air leakage at different air pressure. 


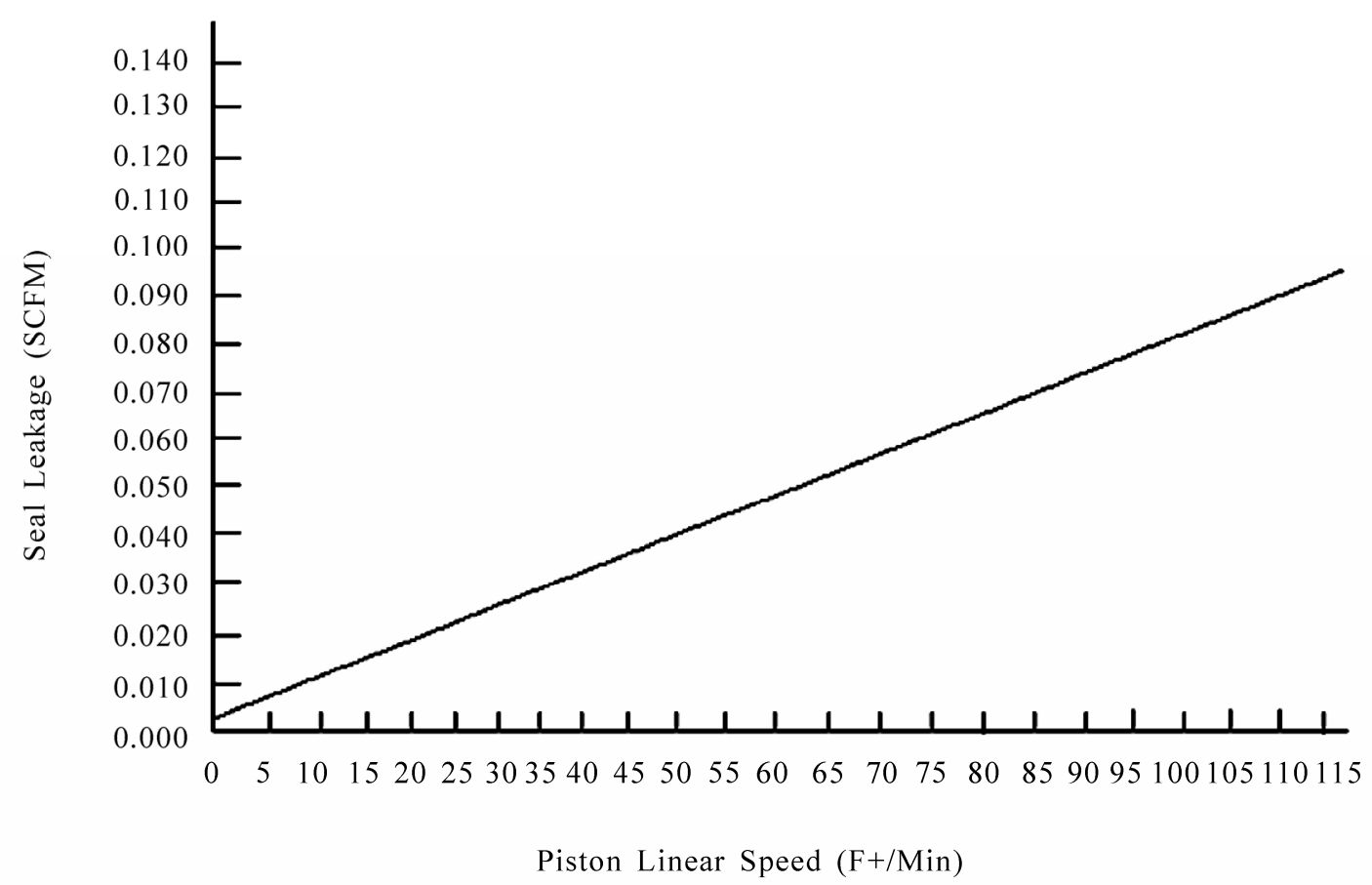

Figure 4. Air leakage vs. piston linear speed.

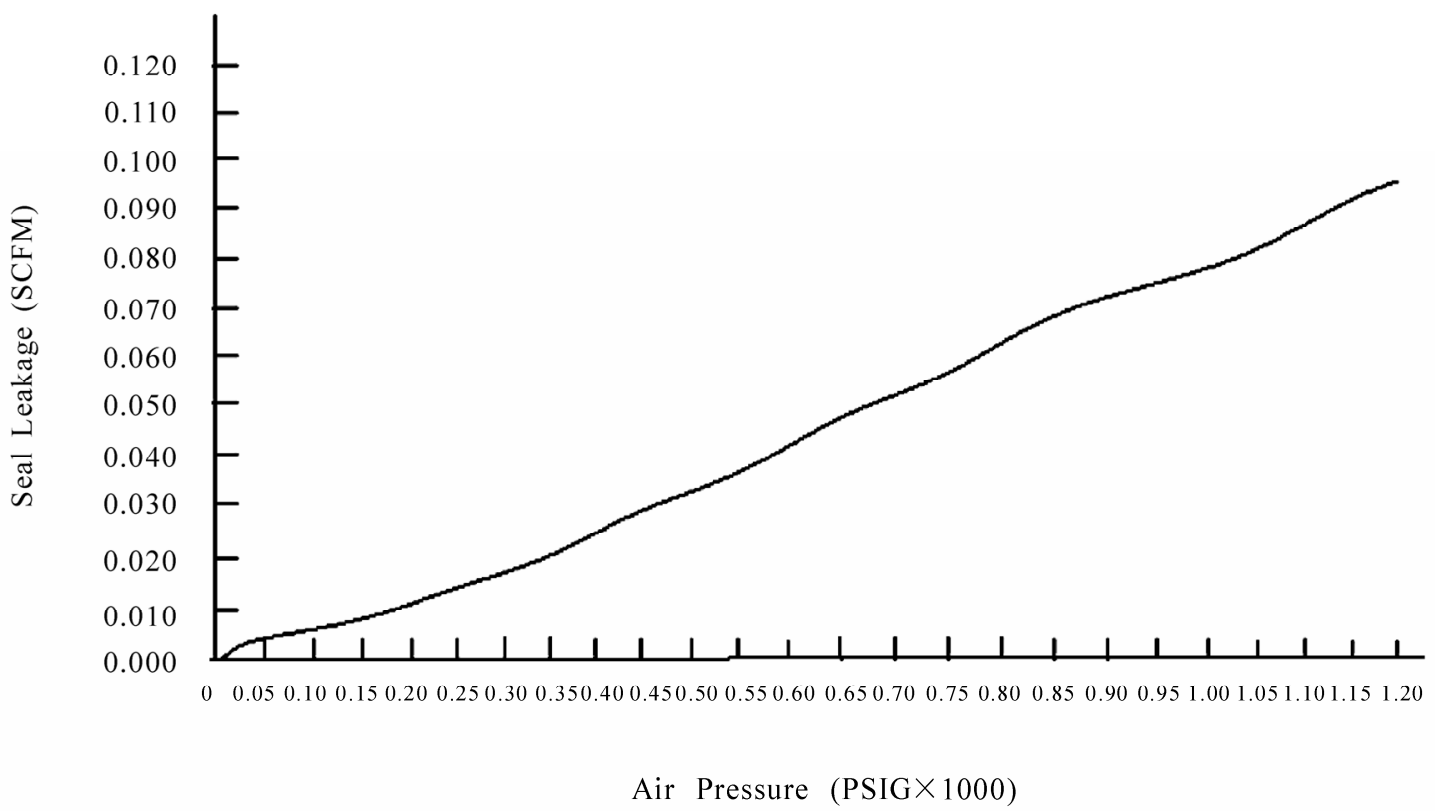

Figure 5. Air leakage vs. air pressure.

nism has been tested and the preliminary results are shown in Tables 1 and 2.

\section{Computational Simulation Results}

This new magnetic sealing system has also been simu- lated by computational solution and results are indicated in Figures 4 and 5.

Based on the above, the preliminary results from prototype testing and computational simulation are closed to each other, and this verifies the creditability and feasibility of this new magnetic sealing mechanism. 


\section{Conclusions}

Today the oil and gaseous media leakages are the tough and difficult engineering problems that affect the reciprocating machinery function and performance. This new magnetic sealing mechanism has been developed to reduce the oil and gaseous media leakages in reciprocating machinery. All the theoretical mechanical and magnetic analysis, computational simulation, and prototype tests indicated that this sealing mechanism can significantly decrease the oil and gaseous media leakages in reciprocating machinery. Its sealing performance is reliable due to the firmly adhesive and strong forces between the magnetic particles and reciprocating pistons/shafts. This seal mechanism is also durable if compared with regular seals including rubber seal, diaphragm seal, corrugated pipe seal because of less frictional force between surfaces of seal and pistons/shafts in this new sealing mechanism. Moreover, the development of this magnetic sealing mechanism will further contribute to the exploitation, popularization, and application of the rich rareearth elements/materials in today's modern industrial world.

\section{References}

[1] H. Quelle, G. González-Jorge, and L. Domarco, "Mag- netic field cancellation on the surface of superconducting rings: Influence on the flux creep," Cryogenics, Vol. 48 pp. 2-5, 2008.

[2] J. E. Hirsch, "The Lorentz force and superconductivity," Physica A, Vol. 315, pp. 474-476, 2003.

[3] H. González-Jorge, B. Liñares, I. Quelle, E. Carballo, and G. Domarco, "Measurement of critical current in superconducting rings," Measurement Vol. 40, pp. 378-380. 2007.

[4] H. González-Jorge, J. Peleteiro, E. Carballo, L. Romaní, and G. Domarco, "Procedure to induce a persistent current in superconducting cylinders or rings," Applied Physica, Vol. 81, pp. 420-421, 2002.

[5] H. González-Jorge, J. Peleteiro, E. Carballo, and G. Domarco, "Inducting technique and trapped field in ring-shaped Superconductors," Physica, Vol. 433, pp. 132-134, 2005.

[6] P. W. Anderson, "Theory of flux creep in hard superconductors," Physica, Vol. 9, pp. 309-311, 1962.

[7] U. Topal, L. Dorosiskii, H. Ozkan, and H. Yabuz, "Effect of thermal neutron irradiation in boron-doped melt- textured YBCO superconductors," Physica, Vol. 388, pp. 401-403, 2003.

[8] L. Shlyk, G. Krabbes, G. Fuchs, K. Nenkov, and B. Schupp, "Flux pinning and magnetic relaxation in melt-processed $\mathrm{YBa}_{2} \mathrm{Cu}_{3} \mathrm{O}_{7-\mathrm{d}}$ dopped with $\mathrm{Li}$," Journal of Applied Physica, Vol. 96, pp. 371-374, 2004. 


\section{Nomenclature}

$\mathrm{A}_{\mathrm{g}}=$ cross section area of working gap

$\mathrm{B}_{\mathrm{g}}=$ density of magnetic flux in working gap

$\mathrm{B}_{\mathrm{r}}=$ density of magnetic flux

$(\mathrm{BH})_{\max }=$ maximum product of magnetism and energy

$\mathrm{C}=$ coefficient

$\mathrm{D}=$ Width of magnetic steel

$\mathrm{f}=$ coefficient of circuit efficiency

$\mathrm{H}=$ intensity of magnetic field of magnet steel
$\mathrm{H}_{\mathrm{g}}=$ intensity of magnetic field in working gap

$\mathrm{L}=$ length of magnet steel

$\mathrm{L}_{\mathrm{g}}=$ length of working gap

$\mathrm{T}=$ intensity of magnetization

$\mathrm{U}_{0}=$ magnetic conductivity of vacuum

$\mathrm{V}_{\mathrm{g}}=$ volume of working gap

$\mathrm{V}=$ volume of magnet steel

$\mathrm{B}=$ half length of working gap

$\Phi=$ magnetic flux 